\section{Tmaginario como Recurso Turístico: Tierra del Fuego ${ }^{1}$}

\section{María Teresa Luiz ${ }^{2}$}

María Elena Daverio 3

RESUMEN: El presente estudio identifica los mitos, creencias y concepciones que fueron configurando las visiones del espacio patagónico-fueguino y observa los cambios y permanencias en el imaginario colectivo y su incidencia en la invención de la identidad territorial. Se considera que estos materiales, reelaborados en nuevos considera que estos materiales, reelaborados en nuevos
esquemas perceptivos y valorativos y resignificados desesquemas perceptivos y valorativos y resignificados des-
de diferentes sistemas referenciales - cosmovisiones y paradigmas - permiten comprender, junto a otros factores de distinta naturaleza, la situación de Tierra del Fuego como destino turístico emergente.

PALABRAS CLAVE: turismo e imaginario, mitos, creencias y concepciones, imaginario colectivo, identidad territorial, Tierra del Fuego, Argentina.

ABSTRACT: This paper identifies the myths, beliefs and conceptions that had formed the space visions in the Patagonia earth fire, observes the changes and the Patagonia earth fire, observes the changes and the
remaining in the territorial identity creation. It considers that this materials were elaborated in new perceptive plans, more valuable and significant from various systems of reference-cosmic visions and paradigms - leading to of reference-cosm the conclusion that, with other factors of various origins,
the Terra do Fogo situation as a tourist emergent destination.

KEYWORDS: tourism and imaginative, myths, beliefs and conceptions, collective imaginary, territorial identity, Terra do Fogo (Land of Fire), Argentina.

\section{Introducción}

El interés por conocer los fenómenos y procesos vinculados al desarrollo del turismo como práctica social y organización compleja, ha abierto un espacio de investigación en el que convergen miradas y aportes de distintas disciplinas. Desde perspectivas diversas el estudio de la actividad turística fue revelando nuevas alternativas de aproximación a lo social y el turismo fue configurándose como un objeto multidimensional cuyo abordaje permite explicar cuestiones tan diversas como el funcionamiento y racionalidad de los mercados, la orientación de las políticas públicas, las relaciones de la sociedad con la naturaleza y la historia y los cambiosen las necesidades, motivaciones y sensibilidades sociales. Resulta evidente que la investigación turística ha generado un nuevo campo de conocimiento cuya identidad se definiría tanto por el objetivo del análisis como por la pluridisciplinariedad, entendida como convergencia de experiencias investigativas y de horizontes teóricos en el abordaje de problemas específicos.

Valorando las posibilidades que ofrece este espacio de investigación para pensar los a resos que en el presente definen las especificidades de la realidad de Tierra del Fuego, nos aproximamos a la problemática del turismo advirtiendo el impacto de la actividad tanto en las estructuras materiales de la sociedad comoen las simbólicas. En efecto al tiempo que esta actividad se consolida como sector dinámico de la economía provincial, generando condiciones favorables para el crecimiento y el desarrollo, opera a nivel de las representaciones del espacio como fuerza recreadora de la identidad regional.

Centrando el interés en esta última dimensión, analizaremos cómo estas representaciones - síntesis de materiales simbólicos, imaginarios y realescomunicadas en forma verbal y no verbal - han movilizado a los viajeros durante siglos. El deseo de encontrar esas "cosas maravillosas" de las que se tenía noticias ha sido uno de los leitmotivs de quienes se aventuraban a parajes lejanos ${ }^{4}$. El mismo deseo sigue estimulando el interés de los viajeros actuales; en este sentido, el imaginario - "ese rosario de narraciones ensartadas en un macro-relato fluido y ordenador, emblemático y cohesivo como el inconsciente" (Rotker 1999: 12) - es considerado como recurso turístico.

El propósito de este trabajo es identificar los mitos, creencias y concepciones que fueron configurando las visiones del espacio patagónico-fueguino; observar los cambios y permanencias en el imaginario colectivo y su incidencia en la invención de la identidad territorial. Consideramos que estos materiales, reelaborados en nuevoses?uremas perceptivos, valorativos y resignificados desde diferentes sistemas

4. Antonio de Pigafetta, cronista de la expedición de Hernando de Magallanes, inicia su relación declarando: "supe que navegando porel Océano se veían cosas maravillosas y me determinéa asegurarme pormis propios ojos de la veracidad
Trabajo presentado en el $3^{\circ}$ Congreso Latinoamericano de Investigación Turística "Conocimiento: puente hacia la integración y excelencia turística", Universidad Austral de Chile, Valdivia, octubre-noviembre del 2001.

2. Universidad Nacional de la Patagonia "San Juan Bosco", sede Ushuaia (Argentina). 
referenciales - cosmovisiones y paradigmas - permiten comprender, junto con otros factores de distinta naturaleza, la situación de Tierra del Fuego como destino turístico emergente.

\section{Terra Autralis}

\section{Mitos y Creencias de los Europeos}

Uno de los mitos que incidió en los planes europeos desde el descubrimiento del extremo meridional del continente fue el de la existencia del continente Terra Australis. Vigente desde la Antiguedad y durante toda la Edad Media, la creencia emergió en el siglo XVI con las primeras descripciones de las tierras situadas al sur del pasaje hallado por la expedición de Hernando de Magallanes. Sólo así se explica que la Corona española, en el afán de defender sus derechos exclusivos en el Nuevo Mundo, intentara fortificar las angosturas del Estrecho de Magallanes suponiendo que éste constituía la única vía de comunicación interoceánica. Pero ni siquiera el conocimiento del carácter insular de Tierra del Fuego, tras el hallazgo del Cabo de Hornos en 1616, detuvo la búsqueda del misterioso continente. Las instrucciones expedidas por el gobierno francés y el Almirantazgo inglés para las expediciones marítimas destinadas al Atlántico Sur contemplaron hasta bien avanzado el siglo XVIII una posible ocupación de la Terra Australis. Sólo durante el segundo viaje de James Co \& (1772-1775), la navegación por latitudes extremas permitió demostrar su inexistencia. (Luiz y Schillat, 1997: 68-69).

Sin embargo, es posible reconocer resabios de esta creencia en construcciones posteriores. La visión del "fin del mundo" no es más que la continuidad de ideas vinculadas al mito de la frontera como extremo del ecuménico o espacio habitado o habitable por los europeos. Las relaciones de los primeros navegantes contribuyeron a la difusión del itinerario hacia la legendaria Terra Australis y, posteriormente, también la literatura de viajes y ficción recreó algunos de los rasgos que fueron configurando la identidad de estos territorios como frontera ${ }^{5}$; pero la frontera no es sólo el extremo del mundo conocido sino otro u otros mundos imaginarios.

5. Resulta obligada la mención de la obra de Julio Verne, El Faro del Fin del Mundo (1905), narrativa asociada al faro establecido por el Estado argentino en San Juan de Salvamentoen la Isla de los Estados. Entrelas relaciones de viajes podemos citar: George Ch. Musters, A thome with the Patagonians. A Year's wanderingsover untrodden ground from Bentley an I Magellan to the Rio Negro, London, 187 ; Forence Dixie, Wanderings in Patagonia,

\section{Ocupación y Percepción del Territorio}

Los territorios australes generaron en los europeos impresiones tan diversas comoambivalentes. Las expectativas iniciales sobre los beneficies que podíaofrecer a España la ruta descubierta en 1520 promovieron juicios favorables sobre la región y alentaron tempranos planes de ocupación. En efecto, al tiempo que se establecían los primeros asentamientos en el Río de la Plata, se proyectaba el poblamiento del litoral magallánico advirtiéndose el valor estratégico del paso interoceánico y la necesidad de ejercerun control del mismo para asegurar su uso exclusivo y la defensa de las costas americanas del Pacífico. Sin embargo, "el mejor estrecho del mundo", (Pigafetta, 1963: 62), como lo había calificado el cronista de la expedición de Magallanes, pronto se convirtió en ruta de naufragios y escenario de la tragedia. La experiencia de los colonos delas efímeras poblaciones fundadas porPedro Sarmiento de Gamboa en 1594 y las dificultades que ocasionaba a la navegación a vela la utilización de la ruta magallánica, debido a la conformación geográfica del estrecho y a los intensos e inestables vientos de la zona, gravitaría de un modo decisivo en la desvalorización del extremo sur americano y en su posterior abandono por España (Luiz y Schillat, 1997: 13 y ss.).

La idea de la "tierra ignota e inhóspita" cristalizaría finalmente en creencia, entendiendo por tal

no el objeto de creer (un dogma, un programa, etcétera) sino la adhesión de los sujetos a una proposición, al acto de enunciarla teniéndola por cierto; dicho de otra manera, una "modalidad" de la afirmación y no su contenido (Certeau, 1990: 260)

Estas categorías utilizadas para describir la realidad regional demuestran que las relaciones entre 'lo real' y las representaciones "no son nunca transparentes ni inmediatas" (Quintero, 2000: 187). Mientras el calificativo de "ignota" alude al estadodel conocimiento europeo - limitado durante siglos a las costas, las condiciones para la navegación, los sitios de recalada y los recursos disponibles para el abastecimiento de las flotas o para una explotación más sistemática -, el de "inhóspita" da cuenta de las visiones construídas desde los primeros naufragios y a partir del temprano fracaso colonizador.

Fue recién durante el siglo XVIII la creciente utilización de la ruta del Cabo de Hornos y el interés de las potencias rivales de España por contar con bases que aseguraran la utilización de las rutas de navegación interoceánica y la explotación sistemática de los recursos marítimos - pinnípedos y cetáceos -, determinaron un cambio en la valoración de la región constituyéndose durante esta centuria y la siguiente en un espacio de convergencia de intereses de distintos estados; primero de las potencias coloniales, y, posteriormente, de los Estados independientes con aspiraciones de soberanía sobre el mismo. Factores de orden económico y geoestratégico explican la rivalidad internacional y los conflictos que se generaron 
por laposesión de los archipiélagos australes y los territorios patagónicos continentales.

Pero, paradójicamente, mientras se incrementaba el interés en la explotación de los recursos naturales y el poblamiento, se recreaba la idea de la tierra hostil. La noción de "desierto", culminación de estas construcciones, logró revitalizarla precisamente en un momento en el que avance en el conocimiento regional permitía debilitarla.

Charles Darwin, quien se convertía en uno de los científicos más relevantes del siglo XIX, contribuyó a mantener la plurisecular valoración del extremo sudamericano. Su relación, publicada en 1839, dos años después de su arribo a Inglaterra, ofrece pasajes que revelan la estabilidad de los esquemas de percepción europeos o más bien la permanencia de sus matrices.

Entre los paisajes que más hondamente se han grabado en mi ánimo, ninguno aventaja en sublimidad al de las primitivas selvas virgenes, no alteradas por la mano del hombre, bien sean las del Brasil, donde predomina la Vida, bien las de Tierra del Fuego, donde prevalecen la disolución y la muerte.

[...] Al evocar imágenes de lo pasado veo cruzar a menudo ante mis ojos las llanuras de la Patagonia y, con todo eso, están generalmente consideradas como yermas e inútiles. Sólo pueden ser descritas por los caracteres negativos: sin viviendas, sin agua, sin árboles, sin montañas, sin vegetación, fuera de algunas plantas enanas. (Darwin, 1998: 447-448)

La confesión del impactoprovocado por las visiones del "desierto" permite advertir asimismo cómo juega la subjetividad en la “"observación” del paisaje.

¿Por qué, pues - y no soy el único a quien le sucede - por qué estosáridosdesiertos han echado tan profundas raices en mi memoria? ¿.Por qué no hacen otro tanto las verdes y fértiles Pampas, superiores a las extensiones patagónicas en las cualidades apuntadas y en dilatarse más a nivel y producir mayores beneficios al hombre? Dificilmente puedo analizar estossentimientos; pero en parte demandan del libre campodado a la imaginación. (Darwin, 1998: 448)

En las descripciones de Tierra del Fuego y del Estrecho de Magallanes volvemos a encontrar imágenes que condensan el repertorio de nociones empleadas para caracterizar el extremo sud americano:

[...] porel Norte se extendia un paisaje de salvaje magnificencia, perfectamente adaptado al carácter general de Tierra del Fuego. Tenia misteriosa grandeza el paisaje de montaña tras montaña, con los hondos valles intermedios, todo cubierto por una espesa y oscura masa de bosque. A la vez, la atmósfera, en este clima de continuos temporales, que descargan lluvias, piedra y cellisca, parece más sombria que en ninguna parte. En el
Estrecho de Magallanes, mirando derechamente al Sur desde Puerto del Hambre, los canales distantes entre las montañas parecian, por su tenebroso aspecto, conducir a regiones situadas más allá de los confines de este mundo. (Darwin, 1998 257).

En ning'intiempo se presenta con tanta viveza al ánimo la idea del remoto rincón del globe en que uno se halla. (Darwin, 1998: 273).

Hemos anclado en la hermosa bahía de Puerto del Hambre. Nos hallamos a principios de invierno, y nunca hemos contemplado un paisaje más tétrico: los bosques sombrios veteados de nieve, apenas pueden verse con alguna claridad a través de una atmósfera brumosa y de la lluvia menudísima que cae. (Darwin, 1998: 283)

Al pie de los elevados y casi verticales cantiles de nuestro pequeño fondeadero habia un wigwam desierto, comopara recordarnos que a veces el hombrevagapor estasdesoladas regiones [...] Las obras inanimadas de la Naturaleza: roca, hielo, nieve, viento y agua, en guerra unas con otras, pero concertadas contra el hombre, reinaban aqui con soberania absoluta. (Darwin, 1998: 293).

Al hombre habituado a vivir en tierra le basta echar una mirada a esta costa para soña durante una semana con naufragios. peligros y muertes; y con la contemplación de este espectáculo me despedi para siempre de Tierra del Fuego. (Darwin 1998: 294)

El relato de Roberto J. Payró, un periodista argentino que visita Tierra de Fuego a fikcs del siglo XIX, presenta claras semejanzas con las descripciones de naturalista inglés en las referencias al paisaje magallánico:

Alli, a la derecha doblaba el Estrecho hacia el noroeste, entre la peninsula Brunswick y la isla Clarence; enfrente, alzábase un monte rodeado de alturas, y el canal de la Magdalena semejaba cerrada bahia, solitaria y triste. Las rocas peladas, el agua mansa, la recortada costa, el cielo turbio, todo se fundía en una coloración melancólica de tonalidad tan armoniosa, que se sentía no ser pintor para trasladarla al papel con los ligeros toques y las blandas tintas de la acuarela. Era aquello un pais del sueño triste y sentimental, una tierra y un mar, escenario de pasiones insaciadas, de desalientos mortales, de amarguras sin término; alli cabia una novela de descreimiento y desengaño; alli el pincel encontraria el cuadro sugestivo de la aridez de la existencia.

- ¡Qué hermoso es esto, a la verdad! (Payró, 1982: 190-192)

Considerando la elocuencia de estos textos nos limitamos a destacar con los subrayados las notas identitarias de un territorio incorporado definitivamente al imaginario de la frontera. 


\section{Representaciones del Espacio Patagónico}

El análisis de las fuentes históricas permite advertir cómo gravitaron en la dinámica social y económica, los factores geográficos y ambientales; además de otros de orden simbólico (las representaciones del espacio patagónico, construidas desde una particular concepción de la relación sociedad-naturaleza). La concepción de la inhabitabilidad, sustentada en el conocimiento de las condiciones de las áridas zonas costeras, se proyectó a la totalidad del espacio, escasamente conocido, limitando la posibilidad de advertir la diversidad ecológica de un extenso territorio.

Durante el período colonial, estasimágenes que se generan entre los europeos sobre la poca hospitalidad del territorio y de sus habitantes explican el lento avance del poblamiento. Recién a fines del siglo XVIII, frente a las amenazas reales o potencialc - : Estados rivales, la corona española proyectó la ocupación de puntos estratégicos en el litoral sudatlántico; al mismo tiempo, el presente escepticismo de las autoridades respecto a la posibilidad de mantener estos puestos alejados, incidió en el alcance de la empresa pobladora. La ocupación hispana en Patagonia apenas logró sobrepasar las precarias e inconclusas murallas del fuerte emplazado en la desembocadura del río Negro.

Posteriormente, al iniciarse la colonización por iniciativa de los Estados argentino y chileno, durante el último tercio del siglo XIX, la misma visión influyó en la opción por un modelo económico basado en la ganadería ovina que, además de obstaculizar otras alternativas de desarrollo, produjo en fuerte impacto ambiental en Patagonia y la Isla Grande cuyos efectos son evidentes en nuestros días. Esta imagen ha perdurado, prevaleciendo incluso, sobre las referencias proporcionadas por estudios sistemáticos, producto de exploraciones científicas; sin embargo Tierra del Fuego no ha logrado liberarse totalmente del calificativo de "zona inhóspita".

En lasrepresentaciones del espacio percibimos la ambivalencia del imaginario de frontera; en ellas se funden las imágenes del "desierto" y las valoraciones positivas sobre la riqueza natural, la fascinación por lo extraño y el temor a "lo otro", llámese naturaleza salvaje o no socializada, " no-lugar' ' como opuesto a lugar social o “exterioridad absoluta" (Augé, 1992).

Los pasajes citados de la relación de Darwin trasuntan esta ambivalencia como tami.iv la fuerte atracción que genera lo desconocido e inconmensurable:

Las llanuras de la Patagonia son sin limite, apenas se las puede franquear, y, por tanto, desconocidas; llevan el sello de haber permanecido como están hoy durante larguisimas edades, y parece que no ha de haber limite en su duración futura. Si nos pusiéramos en elcaso de los antiguos, que consideraban la tierra comouna llanura rodeada de una zona infranqueable de aguas o de desiertoscaldeados poruncalor irresistible ¿quién no miraria estos limites postreros de las exploraciones humanas con un sentimiento de profunda y vaga curiosidad. (Darwin, 1998: 448).
La idea de la frontera como reto, proyecto, o lugar de iniciativa y, al mismo tiempo, ccsuc confín, periferia y sitio de extrañamiento, gravitó tanto en la definición de las políticas estatales, como en las opciones individuales. La misma ambivalencia se traslada al el slogan oficial 'Tierra del Fuego: promesa y desafío', difundido hace apenas dos décadas para impulsar el crecimiento del entonces Territorio Nacional, cuando la región era escenario de otro conflicto internacionalZ: la controversia por las islas del Canal Beagle.

\section{Turismo y Imaginario en Ushuaia}

En el contexto de los nuevos paradigmas, particularmente del ecologismo, y de los procesos de valorización y patrimonialización de los bienes naturales, los espacios del planeta menos modificados o deteriorados por la acción humana se presentan como destinos privilegiados para las prácticas turísticas.

El nuevo mito del encuentro con la naturaleza prístina, virgen y salvaje ${ }^{6}$ configurado a partir de la conciencia de los desequilibrios ecológicos y la destrucción del ambiente, ha generado nuevas prácticas turísticas - identificadas como turismo de naturaleza, ecoturismo o turismo verde - basadas en el contacto directo con el medio ambiente (Vera, 1997: 142-143).

La consideración dialógica de las ideas de desarrollo humano y ambiente natural permite pensar nuevas relaciones con la naturaleza y, desde esta perspectiva el ecoturismo propone una alternativa de uso de los recursos que responde a la idea de la sostenibilidad, entendida como gestión que integra los planos ecológico, económico y cultural?.

El turismo de naturaleza se proyecta tanto sobre áreas protegidas como sobre espacios de valor ecológico y paisajístico con capacidad de atracción que, aunque no se encuentran bajo dicho régimen, mantienen un grado de escasa transformación. Se observa una creciente orientación del interés hacia estos espacios en un contexto de cambio de las sensibilidades sociales y de revalorización de los bienes naturales, estimándose que el turismo de naturaleza ha crecido a nivel mundial entre un $10 \mathrm{y}$ un 30\% (Ceballos-Lascuráin, 1998: 8)

En esta coyuntura de ampliación de la demanda de espacios turísticos especialmente atractivos por sus condiciones naturales, la Isla Grande de Tierra del Fuego, situada entre los $52^{\circ} 40^{\circ}-55^{\circ} 07^{\prime} \mathrm{S}$ y $65^{\circ} 05^{\prime}-70^{\circ} 15^{\prime} \mathrm{O}$, se constituye en

6. Los mitos no hablan sólo de la cosmogénesis ni del paso de la naturaleza a la cultura sino también de todo lo que concierne a la identidad, al pasado, al futuro, lo posible, lo imposible y de todo lo que suscita la interrogación, la curiosidad, la necesidad, la aspiración. El mito se dirige a la subjetividad, concierne al temor, la angustia, la culpabilidad, la esperanza y les aporta respuestas (Morín, 1994: 173-178). En este sentido, es posible considerar que la ideadel retorno a la naturaleza virgen como aspiración o necesidad de contrarrestar los efectos de la crisisecológica, forma parte đr! !niverso mitológico de la sobremodernidad.

7. La idea se I _zumine en la Carta del Turismo Sostenible de la Conferencia Mundial de Lanzarote (1995) que propone

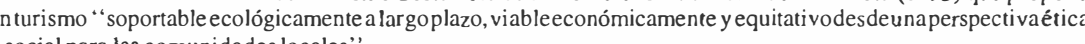
y social para las comunidades locales". 
uno de los destinos privilegiados por las nuevas preferencias. Los flujos turísticos se concentran fundamentalmente en la ciudad más austral, Ushuaia ${ }^{8}$, siendo todavía incipiente en el resto del territorio insular. Esta evolución fue favorecida por las nuevas tecnologías en los transportes y las comunicaciones y el desarrollo de infraestructura local, particularmente con la ampliación del puerto comercial y la construcción del aeropuerto internacional.

La tendencia en alza de los arribos de visitantes es significativa: de 40.656 visitantes en el año 1992 , se pasó a 123.290 en el $2000^{9}$, con una tasa crecimiento interanual pomedio superior al $26 \%$.

Lapráctica turística no presenta un carácter regularen cuantoa la distribución de la afluencia de visitantes a lo largo del año. Mientras en el período estival "temporada alta" (octubre-marzo) se produce una fuerte concentración, durante el inverno se manifiesta una notable retracción ${ }^{10}$. Cabe señalar que la temporada 2000/ 2001 registró un total de 104.416 visitantes, es decir concentró el 85\% de visitantes del total correspondiente al año 2000 (Municipalidad de Ushuaia, Secretaría de Turismo, 2001). Con relación al origen de estos visitantes, las estadísticas proporcionadas por la Secretaría de Turismo de Ushuaia (2001) indican que a partir de la temporada 1994/1995 los extranjeros constituyen más del 50\% de los visitantes, llegando a un $69 \%$ en la temporada $2000 / 2001^{11}$.

En los últimos años el volumen de visitantes cruceristas ha aumentado notablemente llegando a representar el 49,6\% sobre el total de llegadas durante la última temporada al ta (Municipalidad de Ushuaia, Secretaría de Turismo, 2001). Por otra parte, los flujos de turismo marítimo mundial a la Antártida han experimentado un importante crecimiento: de 6.458 pasajeros en la temporada 1992/1993 a 12.260 en la temporada 2000/2001 ${ }^{12}$. Durante esta última 11.489 pasajeros transitaron por el puerto de Ushuaia en su viaje al Continente Blanco. Debemos señalar que el turismo marítimo antártico en tránsito a través de Ushuaia ha aumentado progresivamente ${ }^{13}$, llegando a representar el $94 \%$ del turismo marítimo antártico mundial en 'a última temporada. (Gobierno de la Provincia de Tierra del Fuego, Secretaría de Turismo, 2001).

Capital de la provincia argentina de Tierra del Fuego, Antártida e Islas del Atlántico Sur

Total de visitantes año 1993: 48.216; año 1994: 55.738; año 1995: 55.927; año 1996: 58.452; año 1997: 65.083; año 1998: 102.063; año 1999: 119.569. (Secretaria de Turismo - Municipalidad de Ushuaia, 2001).

(1920) 1996, 47.564; 1996/1997, 47.968; 1997/1998, 69.776; 1998/1999, 96.781; 1999/2000, 94.906. (Secretaria de Turismo - Municipalidad de Ushuaia; 2001)

11. Evolución del turismo receptivo por temporada alta -Ushuaia-: 1993/1994, visitantes nacionales: $59 \%$, visitantes extranjeros: $41 \% ; 1994 / 1995$, visitantes nacionales: $43,2 \%$, visitantes extranjeros: $56,8 \%$; 1995/1996, visitantes nacionales: $33,2 \%$, visitantes extranjeros: 66,8\%; 1996/1997, visitantes nacionales: $32,9 \%$, visitantes extranjeros: 67,1\%; 1997/1998, visitantes nacionales: 32,2\%, visitantes extranjeros: 67,8\%; 1998/1999, visitantes nacionales: $30,7 \%$, visitantes extranjeros: $69,3 \% ; 1999 / 2000$, visitantes nacionales: $31,3 \%$, visitantesextranjeros: 68,7\%; 2000 / 2001 , visitantes nacionales: $30,9 \%$, visitantes extranjeros: $69,1 \%$

12. Pasajeros mundiales por temporada: 1993/1994: 7.957; 1994/1995: 8.185; 1995/1996: 9.212; 1996/1997: 7.322; 1997/1998: 9.380; 1998/1999: 9.850; 1999/2000: 13.650. (Secretaria de Turismo de Tierra del Fuego, 2001)

13. Pasajeros Ushuaia por temporada y porcentaje sobre pasajeros mundiales: 1992/1993: 4.116, 64\%; $1993 / 1994$
$4.689,59 \% ; 1994 / 1995: 7.325,89 \% ; 1995 / 1996: 8.322,90 \%: 1996 / 1997: 6389,87 \% ; 1997 / 1998: 8560,91 \%$; 1998/1999: 9.135, 93\%; 1999/2000: 12.967, 95\%. (Secretaría de Turismo de Tierra del Fuego, 2001).
El paisaje natural es sin duda, el referente patrimonial más importante de la isla: en el Canal Beagle, los Andes, los glaciares, el bosque subantártico y el mar se presentan juntos en una unidad escénica de singular atractividad.

Este espacio asume así su función turística a partir de los nuevos significados del patrimonio natural. Siguiendo a Prats (1997: 22) entendemos que el patrimonio está determinado por sus connotaciones simbólicas en el imaginario colectivo, es decir, su capacidad para representar simbólicamente una identidad. Y precisamente en este caso, la representación de Tierra del Fuego como "paraíso natural” juega un papel decisivo como rasgo identitario.

El sacerdote Alberto de Agostini, quien visitó la isla en las primeras décadas del siglo XX, dejó relatos admirables del paisaje fueguino como "visiones posibles". La descripción de un atardecer estival nos exime de todo comentario respecto a la manifestación de las fuerzas naturales en estas latitudes.

La tarde de aquel dia fue una de las más maravillosas de que he podido disfrutar en la Tierra del Fuego.

Elsol, que hasta entonces habia asomadode vez en cuando, reina ahora soberano en toda su majestad y esplendor en un cielo terso y azul, derramando un calorcillo tan confortable como desacostumbrado. Las cumbres de los montes, veladas todavia acá y allá por las nubes, vanpocoa pocodespejándosecomo porun esfuerzo seguido, casidesperezándose después de larga pesadilla, afanosa y terrible.

A las blandas caricias del sol, los nevados e inmaculados picos tienen una expresión de docilidad y candor encantadora, un aspecto de humildes y serenas virgenes, que ignoran toda pasión, porque el fatal destino las ha condenado a vivir lejos, muy lejos, en las soledades antárticas, perennemente azotadas por los vientos y las tempestades.

A medida que avanza la noche, desaparecen las brisas y la naturaleza toda cae en profundo silencio. Reflejan con la limpidez de un espejo las aguas del Canal a las vagas sombras de la floresta y las empinadas laderas de los montes; no se oye ni el murmullo de las hojas, ni el zumbido de los insectos, ni el canto de las aves; todo calla en aquella misteriosa soledad donde parece como si la vida se hubiera apagado de pronto; tan sólo de vez en cuando llega hasta nosotros el ligero ruido de alguna cascada lejana, que resuena en nuestros oídos como el recuerdo de una dulce y nostálgica melodía.

Se oculta el sol. Alrededor de su disco que parece posarse sobre las gélidas crestas de los montes del sur, se amontonan densas capas de nubes resplandecientes como oro, de las cuales desciende una lluvia de luz vivisima sobre las aguas del canal. A medida que se $:$ ن vniendo el sol detrás de las montañas acentúa sus tintas el cielo, pasando por indefinida gradación de tonos, desde el oro al rojo de púrpura, desde el bermejo al azulceleste; y un mar de graciosos cirros aparecidos de pronto sobre ese fondo, se doran en los bordes y se iluminan con los repentinos relampagueos desprendidos de aquel incendio, que debajo de ellos arde y flamea.

Es una paleta deslumbrante de colores que se cambian y se suceden con la rapidez de rayo. Acá se apagan, allá adquieren mayorfuerza y resplandor o cambian diametralmente de tono, de manera que, en pocos instantes un pintor veria desaparecer de repente los 
tintes fijados pocos momentos antes, mientras otros nuevos, hermosísimos, se le aparecen con prodigiosa fecundidad.

Sehar'. 'r.jagado ya los últimos rayosdel sol, ha cesado todo aliento de vida, y las montañas y las aguas se velan con la penumbra de la noche, que avanza lentamente y adormece entre sus sepulcrales brazos a toda la naturaleza.

Nunca como en estas horas de estática contemplación, lejos de todo ser humano, en las misteriosas soledades de las selvasyde losmontes, ante aquellossublimes espectáculos de la creación, habia sentido el lenguaje de la naturaleza que con tan delicados acentos me hablaba y producia en mi tan profundas y vivas emociones. (De Agostini, 1929: 72-79).

Creemos que, además de la composición estética, el texto presenta otras virtudes que justifican esta transcripción completa: a quien ha vivenciado este "encuentro" permite recrear visiones de profundo impacto emocional y ofrece al viajero la posibilidad de anticipar una experiencia extraordinaria.

Junto con la búsqueda del contacto con la naturaleza, gravitan en las opciones turísticas actuales, particularmente entre los visitantes extranjeros, lasrepresentaciones del espacio como confín y frontera. Estas motivaciones - donde se elige como destino de preferencia a Ushuaia - se constatan en los datos proporcionados por la Secretaría de Turismo. Entre la opciones incluidas en la encuesta, los ítems más elegidos son: naturaleza, ciudad del fin del mundo, paisaje, cercanía al continente antártico y curiosidad. Si tomamos los porcentajes de losítems naturaleza y paisaje, juntos, se crnfirma lo anteriormente señalado respecto decuál sería el referente patrimoniai más importante en este espacio. Por otro lado, los porcentajes correspondientes al ítem ciudad del fin del mundo, no sólo resultan tan elevados como los de la naturaleza, sino que se mantienen constantes desde la temporada 1995/1996 hasta la última 1999/2000. Finalmente, el crecimiento porcentual en el ítem cercanía al continente antártico, coincide con el aumento de los flujos turísticos marítimos antárticos a través del puerto de Ushuaia ${ }^{14}$.

14. Preferencia por el destino Ushuaia, visitantes nacionales por temporada alta (en \%): Conocer el pais: 1995/1996: 35,60\%, 1996/1997: 34,46\%, 1997/1998:31,58\%, 1999/2000: 22,22\%: Nuturaleza: 1995/1996: 20,73\%, 1996 1997: 17,23\%, 1997/1998: 14,97\%, 1999/2000: 13,42\%;Ciudad del fin del mundo: 1995/1996: 15,60\%, $1996 /$ 1997: 17,23\%, 1997/1998: 14,97\%, 1999/2000: 13,42\%;Ciudad del fin del mundo: 1995/1996: 15,60\%, $1996 /$ 1998: 13,88\%, 1999/2000: 13,75\%; Curiosidad: 1995/1996: 6,24\%, 1996/1997:4,30\%, 1997/1998: 6,01\%, $1999 /$ 2000:-; Cercunia a la Antúrtida: 1995/1996: 2,39\%, 1996/1997:4,71\%, 1997/1998: 3,93\%, 1999/2000: 1,65\%. Preferencia por el destino Ushuaia, visitantes extranjeros por temporada alta (en \%): Conocer el país: 1995/1996 18,35\%, 1996/1997: 30,87\%, 1997/1998: 18,14\%, 1999/2000: 11,99\%; Naturaleza: 1995/1996: 22,20\%, 1996/ 1997: 26,66\%, 1997/1998: 19,56\%, 1999/2000: 26,51\%; Ciudad del fin del mundo: 1995/1996: 23,49\%, $1996 /$ 1997: 23,59\%, 1997/1998: 10, 16\% 1999/2000: 24,42\%; Paisaje: 1995/1996: 15,05\%, 1996/1997: 22,77\%, 1997/ 1998:12,02\%, 1999/2000: 18,04\%, Curiosidad: 1995/1996:8,99\%, 1996/1997:11,18\%, 1997/1998: 1,86\%, 1999/ 2000: - Cercania a la Antúrtida: 1995/1996: 9,36\%, 1996/1997: 10,26\%, 1997/1998: 9,73\%, 1999/2000 del 1998 iu encuesta a turistas se realiza cada dos años.

\section{Conclusión}

Partiendo de la consideración de que las representaciones inciden en las prácticas sociales y que éstas a su vezmoldean las representaciones, nos propusimos visualizar cómo las visiones de Tierra del Fuego como "confín", "frontera" y " "paraíso natural" gravitan en las prácticas turísticas estimulando el interés en el conocimiento de la región. También advertimos que en el presente estas prácticas recrean oresignifican el contenido de las representaciones del espacio, contribuyendo a afirmar la identidad del extremo austral como lugar donde aún es posible proyectar nuevas y viejas utopías. Finalmente, desde esta aproximación al imaginario como recurso turístico hemos intentado ampliar la reflexión sobre las complejas relaciones entre el mito y la realidad, reconociendo la necesidad de contemplar los efectos de su retroalimentación en los procesos sociales.

\section{Bibliografio}

AUGE, Marc. 1992. Los "no-lugares". Espacios del anonimato. Una antropologia de la sobremodernidad. Barcelona: Gedisa.

CEBALLOS-LASCURAIN, Héctor. 1998. Ecoturismo. Naturaleza y desarrollo sostenible. México: Diana. CERTEAU, Michelle de. 1990. L' Invention du quotidien. Paris: Gailimard. (Arts de Faire, 1)

DARWIN, Charles. 1998.Diariodel viaje de un naturalistaalrededordelmundo [1845]. Buenos Aires: Elefante Blanco DE AGOSTINI, Alberto M. 1929. Mis viajes a la Tierra del Fuego. Milann: Editorial Prof. G. De Agostini

DIXIE, Florence. 1996. A través de la Patagonia [1880]. Punta Arenas: Universidad de Magallanes.
GOBIERNO DE LA PROVINCIA DE TIERRA DEL FUEGO. ANTARTIDA E ISLAS DEL ATLANTICO SUR. SECRETARIA DE TURISMO DE TIERRA DEL FUEGO. 2001. Ushuaia 'Puerta de entrada a la Antártida' Informe sobre el Tránsito de Turismo Antártico a través de Ushuaia Temporada 2000-200I Ushuaia: Oficina Antárticar LUIZ, María Teresa y Monika SCHILLAT. 1997. La frontera austral. Tierra del Fuego, 1520-1920. Cádiz:Universidad de Cádiz.

MORIN, Edgar. 1994. El método. El conocimiento del conocimiento. Madrid: Cátedra

MUNICIPALIDAD DE USHUAIA, DIRECCION DETURISMO. 1996, 1997, 1998 y 2000. El turismo en Ushuaia Informe Estadistico. Año 1995 y temporada 1995/1996; Año 1996 y temporada 1996/1997; Año 1997 y temporada $1997 / 1998$ y $A$

MUNICIPALIDAD DEUSHUAAA, SECRETARIA DETURISMO. 2001. EITurismoen Ushuaia. Informe Estadistice. Año $2000 \mathrm{y}$ temporada 2000/2001. Ushuaia.

MUSTERS, George Ch. 1979. Vida entre los patagones. Un año de excursiones por tierras no frecuentadas desde el Estrecho de Magallanes hasta el Río Negro. Buenos Aires: Solar/Hachette.

PAYRO, Roberto J. 1982. La Australia argentina. Excursión periodística a las costas patagónicas. Tierra del Fuego e Isla de los Estados. Buenos Aires: Centro Editor de América Latina.

. Espasa-Calpe

作 investigación social, en Cora Escolar (comp.). Topografiud de la investigación. Buenos Aires: Eudeba.

ROTKER, Susana. 1999. Cautivas. Buenos Aires: Ariel.

VERA, Fernando J. 1997. Análisis territorial del turismo. Una nueva geografía del turismo. Barcelona: Ariel.

Recibido en $5 / 11 / 2002$

Aprobado en 15/12/2002 